\title{
Foveal Sensitivity and Morphology in Major and Macular Branch Retinal Vein Occlusion
}

\author{
Hidetaka Noma $^{*}, 1$, Katsunori Shimada ${ }^{2}$ and Tatsuya Mimura ${ }^{3}$ \\ ${ }^{\prime}$ Department of Ophthalmology, Yachiyo Medical Center, Tokyo Women's Medical University, Chiba, Japan \\ ${ }^{2}$ Department of Biostatistics, STATZ Institute Inc., Tokyo, Japan \\ ${ }^{3}$ Department of Ophthalmology, Medical Center East, Tokyo Women's Medical University, Tokyo, Japan
}

\begin{abstract}
Purpose: To determine whether foveal thickness, foveal volume, visual acuity, and foveal sensitivity after intravitreal injection of triamcinolone acetonide (IVTA) are influenced by the extent of occlusion (major versus macular branch retinal vein occlusion (BRVO)).

Materials and Methodology: In this interventional case series, 22 eyes of 22 BRVO patients with macular oedema were treated by IVTA. Patients were divided into 2 groups according to the site of occlusion, with the Major group having occlusion of a major retinal vein and the Macular group having occlusion of a macular venule. Foveal sensitivity was measured by microperimetry before IVTA and 3 and 6 months after IVTA. Visual acuity was converted to logarithm of the minimal angle of resolution (logMAR) values. Foveal thickness and macular volume were measured by optical coherence tomography before IVTA and 3 and 6 months after IVTA.
\end{abstract}

Results: Foveal thickness and foveal volume showed significant improvement from before to 3 and 6 months after IVTA in both groups (all $\mathrm{P}<0.001$ ). Visual acuity also showed significant improvement from before to 3 and 6 months after IVTA in both groups ( $\mathrm{P}=0.001$ and $\mathrm{P}=0.022$, respectively). Moreover, foveal sensitivity was significantly improved from before to 3 and 6 months after IVTA in the Major group $(\mathrm{P}<0.001)$. Foveal sensitivity also increased from before to 3 and 6 months after IVTA in the Macular group, but not significantly. There were no significant differences in the trend profiles of foveal thickness, foveal volume, visual acuity, and foveal sensitivity between the Major and Macular groups.

Conclusions: These results suggest that IVTA may be effective for improving foveal morphology, visual acuity, and foveal sensitivity in BRVO patients regardless of the site of occlusion.

Keywords: foveal thickness, foveal sensitivity, triamcinolone acetonide, branch retinal vein occlusion, macular oedema, site of occlusion.

\section{INTRODUCTION}

In patients with branch retinal vein occlusion (BRVO), macular oedema is the complication that is most likely to threaten vision [1]. An increase of pressure in the macular capillaries leads to impairment of the endothelial bloodretinal barrier and increases vascular permeability, resulting in the onset of macular oedema [2]. Clinically, BRVO is classified into major (first-order) and macular (second-order) subtypes based on the site of occlusion [3, 4]. In many respects, the clinical and angiographic findings of patients with macular BRVO resemble those of patients with major BRVO. The severity of major BRVO depends on the vein that is occluded and there can be a wide range of complications. While patients with macular BRVO are unlikely to develop neovascularization because of the smaller area of the retina affected, they frequently suffer from macular oedema and visual impairment [5].

*Address correspondence to this author at the Department of Ophthalmology, Yachiyo Medical Center, Tokyo Women's Medical University, 477-96, Owada-shinden, Yachiyo, Chiba 276-8524, Japan; Tel: 81-47-450-6000; Fax: 81-47-458-7047; E-mail: noma-hide@umin.ac.jp
Macular oedema in BRVO patients can be treated by the intravitreal injection of anti-VEGF agents [6] or triamcinolone acetonide (IVTA) [7], as well as by grid laser photocoagulation [8] and pars plana vitrectomy (PPV) [9]. All of these methods have been reported to improve both visual acuity and macular oedema. However, previous studies evaluated visual function on the basis of visual acuity alone, although macular oedema usually involves the macula beyond the fovea, suggesting that an objective and reproducible method of measuring retinal function could provide more accurate assessment of the response to treatment. The Micro Perimeter 1 (MP-1) is an instrument that measures retinal sensitivity and it combines digital fundus imaging with automated perimetry [10]. We previously demonstrated that retinal thickness and retinal volume are more closely associated with retinal sensitivity than with best-corrected visual acuity (BCVA) in BRVO patients who had macular oedema [11]. Thus, visual acuity (which only reflects foveal function) may be an inadequate parameter for evaluating the response of these patients to treatment, and it is possible that the functional prognosis could be better assessed by measuring retinal sensitivity with the MP-1. However, little is known about the influence of 
the site of occlusion on retinal sensitivity in BRVO patients after IVTA. Accordingly, we investigated whether foveal thickness, foveal volume, visual acuity, and foveal sensitivity after IVTA were influenced by the site of occlusion (major versus macular) in patients with BRVO.

\section{MATERIALS AND METHODOLOGY}

\section{Patients}

We studied 22 consecutive patients (22 eyes) who had macular oedema with BRVO and were treated with IVTA. Between July 2008 and August 2011, these 22 patients with a mean age of $69.4 \pm 9.4$ years (15 women and 7 men) were prospectively enrolled in this uncontrolled study at the Department of Ophthalmology of Tokyo Women's Medical University. Each patient received a comprehensive ophthalmologic examination, including the measurement of BCVA and intraocular pressure (IOP), indirect ophthalmoscopy, and slit-lamp biomicroscopy with a contact lens before IVTA and at 3 and 6 months after treatment. We graded nuclear, posterior subcapsular, and cortical cataract according to the new World Health Organization Simplified Cataract Grading System, and subjects with cataract $\geq$ grade II (nuclear, posterior subcapsular, or cortical) were defined as having cataract [12]. This study was approved by the Institutional Ethics Committee and adhered to the tenets of the Declaration of Helsinki. Informed consent was provided in writing by each patient.

The inclusion criteria were eyes with a foveal thickness greater than $300 \mu \mathrm{m}$ and a visual acuity equal to or less than 20/33.3. The following 8 exclusion criteria were employed: prior ocular surgery, diabetes mellitus with diabetic retinopathy, prior macular laser photocoagulation, prior intravitreal treatment with anti-VEGF agents or prior IVTA, prior ocular inflammation, severe retinal haemorrhage (including bleeding that involved the intrafoveal or subfoveal spaces), coexisting epiretinal membrane or glaucoma, and retreatment during the 6-month follow-up period. Patients with severe retinal haemorrhage were excluded because of possible bias when assessing visual function. Among the 22 patients, 13 had superior BRVO and 9 had inferior occlusion. The patients were divided into 2 groups according to the site of venous occlusion; Major group (occlusion of one of the major branch retinal veins) and Macular group (occlusion of one of the macular venules) $[3,4]$.

\section{Treatment by IVTA}

In all 22 patients, IVTA was delivered under local anaesthesia. Each patient received $4.0 \mathrm{mg}$ of triamcinolone acetonide in a volume of $0.1 \mathrm{ml}$. Both groups were assessed according to the same study protocol. Injection was done through the pars plana (3-4 mm posterior to the limbus) with a sterile technique, and prophylactic topical antibiotics were applied for 1 week afterward. Patients were followed for at least 6 months. Recurrence of macular edema was defined as an increase of foveal thickness by $>100 \mu \mathrm{m}$ compared with that at 3 months after IVTA in patients whose foveal thickness had decreased to $<300 \mu \mathrm{m}$ at 3 months [13].
Macular oedema recurred in 4/22 eyes (18\%) from the Major group, but these 4 patients refused further treatment.

\section{Fundus Examination}

At baseline ophthalmoscopy and biomicroscopic examination using a slit-lamp with a fundus contact lens were performed. Patients also underwent standard fundus color photography and fluorescein angiography, using a Topcon TRC-50EX fundus camera, image-net system (Tokyo Optical Co. Ltd., Japan), and preset lens with a slitlamp.

To assess ischaemic retinal vascular occlusion, the ischaemic area of the retina was measured angiograms by a masked grader using Scion Image public domain software [14-16]. In brief, the optic disc was outlined with a cursor and its area was measured. Then the nonperfused part of the retina was outlined and its area was determined, after which the nonperfused area was divided by the disc area to calculate an index of retinal ischaemia. Thus, we used the disc area as a unit to evaluate the ischemic area.

\section{Measurement of BCVA}

Each patient underwent measurement of BCVA in decimal units on a Landolt chart by an orthopticist using an SC-2000 System (Nidek, Gamagori, Japan). Chart brightness was set at $80-320 \mathrm{~cd} / \mathrm{m}^{2}$ and contrast was set at more than $74 \%$. Data were converted to the logarithm of the minimum angle of resolution scale (logMAR).

\section{Optical Coherence Tomography}

An OCT 3000 Zeiss or Cirrus HD-OCT instrument (Carl Zeiss Meditec, Dublin, CA, USA) was used to measure the foveal thickness. Measurement was done in the vertical cross-section with the instrument centered on the fovea and in the fast macular thickness mode. The foveal thickness was defined as the distance between the inner surface of the neurosensory retina and the retinal pigment epithelium. Foveal thickness and foveal volume were respectively calculated as the average retinal thickness and volume within a circle of $500 \mu \mathrm{m}$ radius centered on the fovea. These measurements were automatically performed by computer software.

\section{Microperimetry}

Fundus-monitored microperimetry was done with an MP1 system (Nidek, Gamagori, Japan), using an infrared fundus camera controlled by software that automatically tracked movement of the fundus (evaluating shifts in the $x$ and $y$ directions with respect to a reference frame obtained at the start of examination). In all examinations, Goldmann III stimuli were randomly presented according to a 4-2-1 double staircase strategy. Stimulus intensity was varied from 0 to 20 decibels $(\mathrm{dB})(0 \mathrm{~dB}$ corresponded to the strongest signal intensity of $127 \mathrm{~cd} / \mathrm{m}^{2}$ ) in $1-\mathrm{dB}$ increments, and the stimulus duration was set at $200 \mathrm{~ms}$. The size of the target for fixation was varied according to the patient's visual acuity. Background illumination was set at $1.27 \mathrm{~cd} / \mathrm{m}^{2}$. Foveal sensitivity was calculated as the average retinal sensitivity within a circle of $500 \mu \mathrm{m}$ radius centered on the fovea, and 
was determined at five locations covering the central $4^{\circ}$ field [11].

\section{Statistical Analysis}

All analyses were performed with SAS System 9.1 software (SAS Institute Inc., Cary, North Carolina, USA). Results are presented as the mean $\pm \mathrm{SD}$ or as the frequency. One-way or two-way repeated measures ANOVA and a post-hoc $t$-test with Bonferroni's correction were used to evaluate changes of foveal thickness and volume, visual acuity, and foveal sensitivity. Two-tailed $\mathrm{P}$ values of less than 0.05 were considered to indicate statistical significance.

\section{RESULTS}

The characteristics of the Major and Macular groups are summarized in Table 1. Among the 22 patients with BRVO, 15 were assigned to the Major group and 7 to the Macular group. The mean age, female/male ratio, prevalence of hypertension, systolic blood pressure, diastolic blood pressure, prevalence of hyperlipidaemia, and duration of BRVO were similar in the Major and Macular groups $(P=0.230, P=0.448, P=0.823, P=0.131, P=0.839, P=0.899$, and $P=0.094$, respectively), but the nonperfused area was significantly larger in the Major group than the Macular group $(P=0.006)$.

Table 1. Baseline Clinical Features of the Two Groups

\begin{tabular}{|l|c|c|c|}
\hline \multicolumn{1}{|c|}{ Findings } & $\begin{array}{c}\text { Major } \\
(\mathbf{N = 1 5})\end{array}$ & $\begin{array}{c}\text { Macular } \\
(\mathbf{N}=7)\end{array}$ & $\begin{array}{c}\boldsymbol{P} \\
\text { Value }\end{array}$ \\
\hline \hline Age (years) & $67.7 \pm 9.4^{\ddagger}$ & $73.0 \pm 9.0^{\ddagger}$ & 0.230 \\
\hline Gender (female/male) & $11 / 4$ & $4 / 3$ & 0.448 \\
\hline Hypertension & 10 & 5 & 0.823 \\
Systolic blood pressure (mmHg) & $133 \pm 13^{\ddagger}$ & $143 \pm 15^{\ddagger}$ & 0.131 \\
Diastolic blood pressure (mmHg) & $84 \pm 12^{\ddagger}$ & $85 \pm 13^{\ddagger}$ & 0.839 \\
\hline Hyperlipidemia & 9 & 4 & 0.899 \\
\hline Duration of BRVO (months) & $3.6 \pm 1.6^{\ddagger}$ & $5.4 \pm 3.3^{\ddagger}$ & 0.094 \\
\hline Nonperfused area (disc areas) & $50.6 \pm 37.0^{\ddagger}$ & $6.2 \pm 12.0^{\ddagger}$ & 0.006 \\
\hline
\end{tabular}

$\mathrm{BRVO}=$ branch retinal vein occlusion; ${ }^{\dagger}$ Mean \pm standard deviation (SD).

In both groups, foveal thickness and foveal volume showed a significant decrease from before IVTA to 3 and 6 months after IVTA (all $\mathrm{P}<0.001$, one-way repeated measures ANOVA). Foveal thickness and volume decreased significantly from before IVTA to 3 or 6 months after IVTA in both groups (all $\mathrm{P}<0.01$, post-hoc $t$-test with Bonferroni's correction) (Fig. 1A, B). However, foveal thickness and volume both increased from 3 to 6 months after IVTA in the Major group, although not significantly $(\mathrm{P}=0.152$ and $\mathrm{P}=0.135$, respectively, post-hoc $t$-test with Bonferroni's correction) (Fig. 1A, B). There were no significant differences in the trend profiles of foveal thickness and volume between the Major group and the Macular group $(\mathrm{P}=0.457$ and $\mathrm{P}=0.476$, respectively, two-way repeated measures ANOVA) (Fig. 1A, B).
(A)

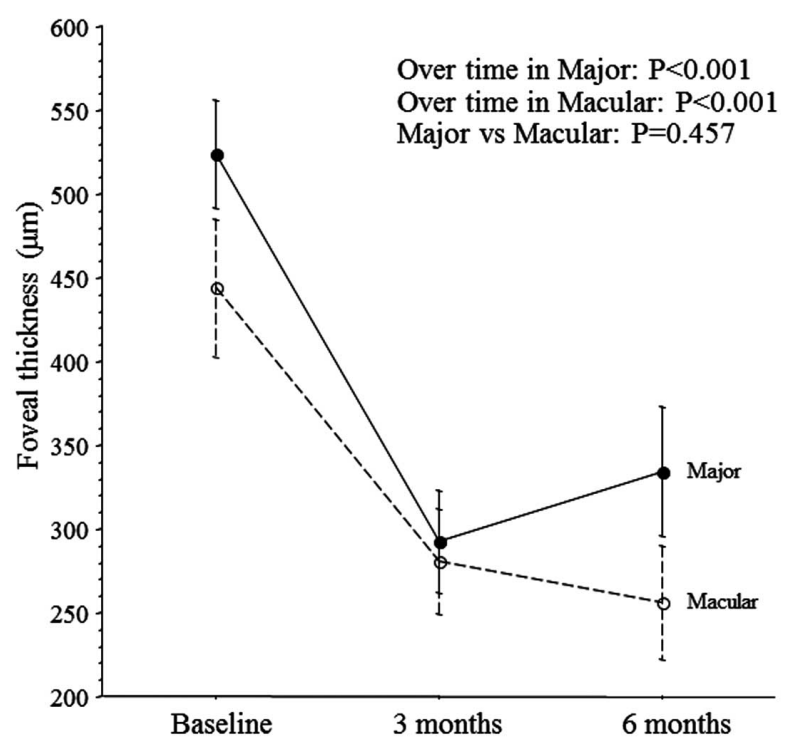

(B)

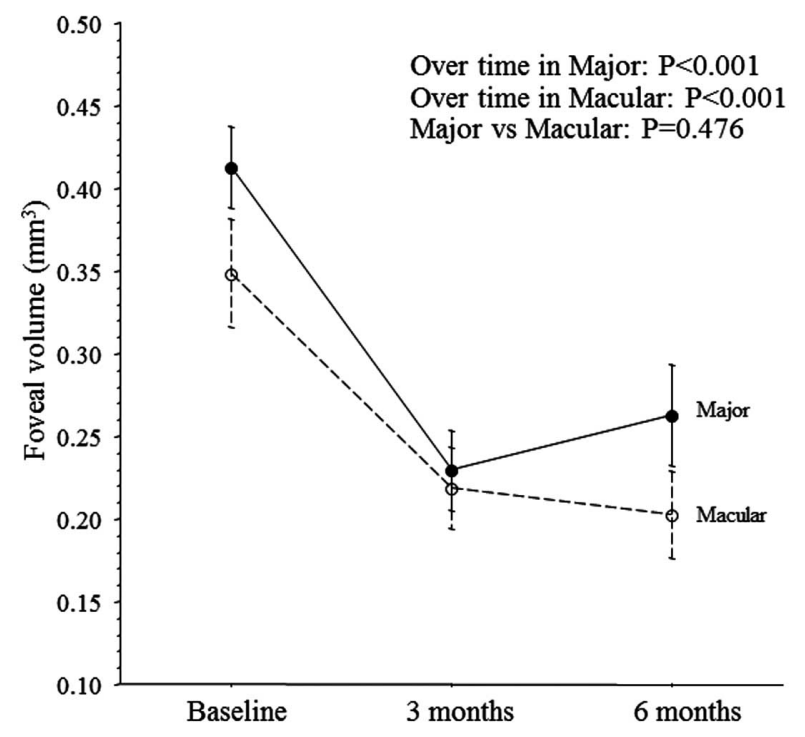

Fig. (1). Trend profiles of foveal thickness and volume after intravitreal injection of triamcinolone acetonide (IVTA) in BRVO patients with macular oedema. (A) In the Major group and the Macular group, the foveal thickness decreased significantly from before IVTA to 3 and 6 months after IVTA $(\mathrm{P}<0.001$ and $\mathrm{P}<0.001$, respectively). There was no significant difference in the trend profile of foveal thickness between the two groups $(\mathrm{P}=0.457)$. (B) In the Major group and the Macular group, the foveal volume decreased significantly from before IVTA to 3 and 6 months after IVTA $(\mathrm{P}<0.001$ and $\mathrm{P}<0.001$, respectively). There was no significant difference in the trend profile of foveal volume between the two groups $(\mathrm{P}=0.476)$.

In the Major group and the Macular group, visual acuity showed significant improvement from before IVTA to 3 and 6 months after IVTA $(\mathrm{P}=0.001$ and $\mathrm{P}=0.022$, respectively, 
one-way repeated measures ANOVA) (Fig. 2A). In the Major group, foveal sensitivity also showed a significant increase from before IVTA to 3 and 6 months after IVTA $(\mathrm{P}<0.001$, one-way repeated measures ANOVA). Although foveal sensitivity increased from before IVTA to 3 and 6 months after IVTA in the Macular group as well, the changes were not significant $(\mathrm{P}=0.456$, one-way repeated measures ANOVA) (Fig. 2B). There were no significant differences in the trend profiles of visual acuity and foveal sensitivity between the Major and Macular groups $(\mathrm{P}=0.640$ and $\mathrm{P}=0.502$, respectively, two-way repeated measures ANOVA) (Fig. 2A, B).

Up to 6 months after IVTA, two of the 22 patients $(9 \%)$ showed an increase of IOP, but this could be controlled by a change of medication. Neovascular glaucoma was not detected in any of the patients. At baseline before treatment, none of the patients had cataract $\geq$ grade II. There were also no new cases of cataract or progression of existing cataracts and no infectious endophthalmitis after IVTA.

\section{DISCUSSION}

This study showed that foveal thickness and foveal volume were significantly improved from before IVTA 3 and 6 months after IVTA in both the Major group and the Macular group. Triamcinolone acetonide is thought to improve macular oedema by decreasing retinal capillary permeability via its effect on tight junctions [17], or it may inhibit the signaling cascade for VEGF and the VEGF receptor that increases microvascular permeability $[18,19]$. Corticosteroids also prevent the production of various inflammatory molecules $[20,21]$ that promote leukocyte adhesion and breakdown of the blood-retinal barrier [22]. Accordingly, IVTA may have led to a decrease of retinal capillary permeability. However, the foveal thickness and foveal volume of the Major group both increased from 3 to 6 months after IVTA, although not significantly. This may have been because the Major group included four patients with recurrence of macular oedema. In addition, the nonperfused area of the retina was significantly larger in the Major group than the Macular group. We previously reported that vitreous fluid levels of VEGF and sICAM-1 were significantly higher in major BRVO compared with macular BRVO [23]. Therefore, it is possible that higher levels of cytokines in the Major group reduce the response to IVTA over time so that foveal thickness and volume increased from 3 to 6 months in these patients. Because there were no significant differences in the trend profiles of foveal thickness and foveal volume between the Major and Macular groups, our results suggest that the response of foveal thickness and volume to IVTA is similar in patients with either major or macular BRVO. Thus, IVTA seems to improve foveal thickness and volume in BRVO patients regardless of site of the occlusion.

We also found that visual acuity showed significant improvement from before IVTA to 3 and 6 months after IVTA in both groups, and that foveal sensitivity also improved significantly at these times in the Major group. As mentioned above, IVTA may decrease macular oedema, so that visual acuity and foveal sensitivity also improve. However, foveal sensitivity was not significantly increased
(A)

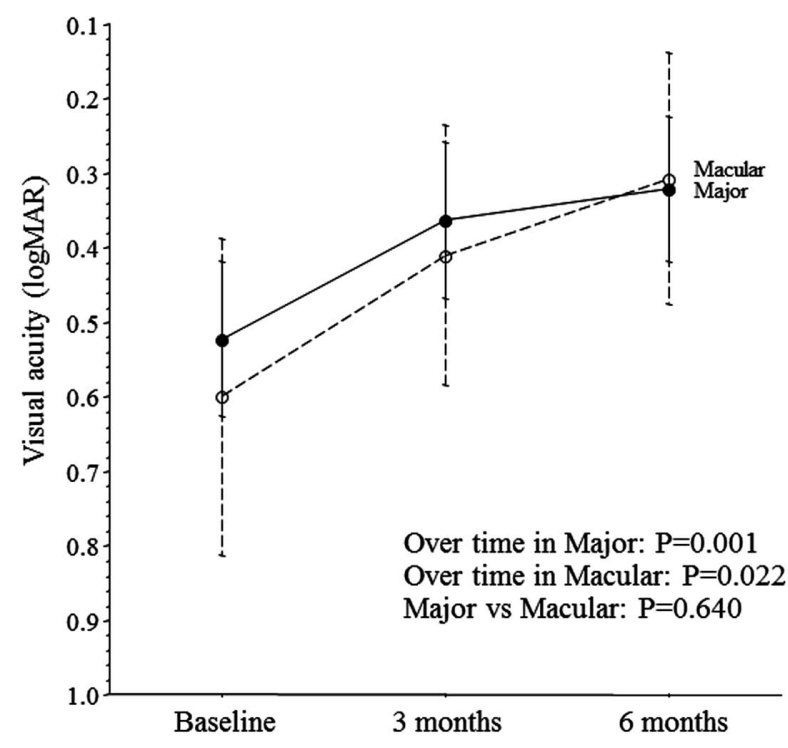

(B)

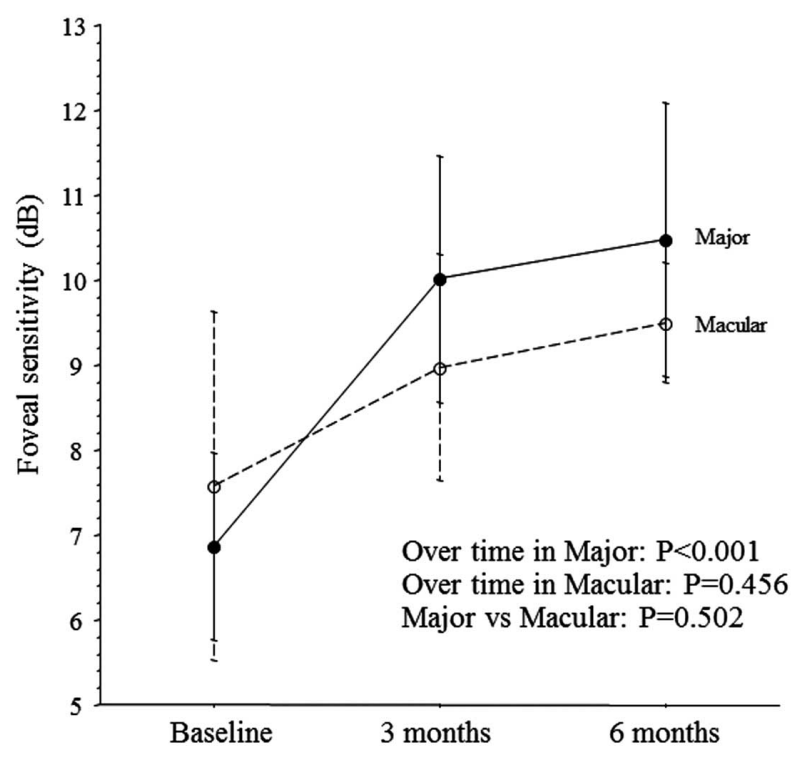

Fig. (2). Trend profile of visual acuity and foveal sensitivity after intravitreal injection of triamcinolone acetonide (IVTA) in BRVO patients with macular oedema. (A) In the Major group and the Macular group, visual acuity improved significantly from before IVTA to 3 and 6 months after IVTA $(\mathrm{P}=0.001$ and $\mathrm{P}=0.022$, respectively). There was no significant difference in the trend profile of visual acuity between the two groups ( $\mathrm{P}=0.640)$. (B) In the Major group, the foveal sensitivity increased significantly from before IVTA to 3 and 6 months after IVTA $(\mathrm{P}<0.001)$. Although foveal sensitivity increased from before IVTA to 3 and 6 months after IVTA in Macular group as well, the changes were not significant $(\mathrm{P}=0.456)$. There was no significant difference in the trend profile of foveal sensitivity between the two groups $(\mathrm{P}=0.502)$.

from before IVTA to 3 or 6 months after IVTA in the Macular group. This may have been because of the small 
number of patients or else may have been due to a lesser change of foveal sensitivity, because the region involved is small in the Macular group. Interestingly, there were no significant differences in the trend profiles of visual acuity and foveal sensitivity between the Major and Macular groups after IVTA. These results suggest that visual acuity and foveal sensitivity showed a similar response to IVTA in patients with both major BRVO and macular BRVO. Thus, visual acuity and foveal sensitivity were improved by IVTA regardless of the site of occlusion. The improvement of visual acuity and foveal sensitivity in both groups may have been related to restoration of the integrity of the inner segment/outer segment (IS/OS), because Ota et al. reported that integrity of the foveal photoreceptor layer is associated with visual acuity after the resolution of macular oedema [24]. However, we could not evaluate the relation between visual acuity or foveal sensitivity and the IS/OS ratio because we used Stratus OCT in 21 patients and spectral domain OCT in only 1 patient. Accordingly, a larger prospective and randomized study is needed to clarify the relation between visual acuity or foveal sensitivity and photoreceptor layer integrity in BRVO patients with macular oedema.

Other limitations of this study were a short follow-up period, small sample size, and lack of a control group. Cataract progression may not have occurred because the follow up period was too short in the present study, so a longer follow up period might reveal progression of cataract with an influence on macular function. Thus, further investigations will be needed to clarify the relationship between foveal function and the site of venous occlusion (major versus macular) in patients with BRVO.

\section{CONCLUSIONS}

There were no significant differences in the trend profiles of foveal thickness, foveal volume, visual acuity, and foveal sensitivity between the Major and Macular groups. These results suggest that IVTA can improve foveal morphology, visual acuity, and foveal sensitivity regardless of the site of occlusion in BRVO patients with macular oedema.

\section{CONFLICT OF INTEREST}

The authors declare that they have no competing interests.

\section{ACKNOWLEDGEMENTS}

Contributions of Authors: H.N. was involved in the design and conduct of study; collection and management of the data were done by H.N.; analysis and interpretation of the data by H.N., K.S., and T.M.; preparation of the first draft of the manuscript by H.N., and review and approval of the manuscript by K.S., and T.M.

\section{REFERENCES}

[1] Michels RG, Gass JD. The natural course of retinal branch vein obstruction. Trans Am Acad Ophthalmol Otolaryngol 1974; 78: OP166-77.
[2] Noma H, Funatsu H, Sakata K, et al. Macular microcirculation and macular oedema in branch retinal vein occlusion. Br J Ophthalmol 2009; 93: 630-3.

[3] Orth DH, Patz A. Retinal branch vein occlusion. Surv Ophthalmol 1978; $22: 357-76$

[4] Lim JW. Intravitreal bevacizumab and cytokine levels in major and macular branch retinal vein occlusion. Ophthalmologica 2011; 225: 150-4.

[5] Joffe L, Goldberg RE, Magargal LE, Annesley WH. Macular branch vein occlusion. Ophthalmology 1980; 87: 91-8.

[6] Brown DM, Campochiaro PA, Bhisitkul RB, et al. Sustained benefits from ranibizumab for macular edema following branch retinal vein occlusion: 12-month outcomes of a phase III study. Ophthalmology 2011; 118: 1594-602.

[7] Scott IU, Ip MS, VanVeldhuisen PC, et al. A randomized trial comparing the efficacy and safety of intravitreal triamcinolone with standard care to treat vision loss associated with macular Edema secondary to branch retinal vein occlusion: the Standard Care vs Corticosteroid for Retinal Vein Occlusion (SCORE) study report 6. Arch Ophthalmol 2009; 127: 1115-28.

[8] The Branch Vein Occlusion Study Group. Argon laser photocoagulation for macular edema in branch vein occlusion. Am J Ophthalmol 1984; 98: 271-82.

[9] Tachi N, Hashimoto Y, Ogino N. Vitrectomy for macular edema combined with retinal vein occlusion. Doc Ophthalmol 1999; 97: 465-9.

[10] Yamaike N, Kita M, Tsujikawa A, Miyamoto K, Yoshimura N. Perimetric sensitivity with the micro perimeter 1 and retinal thickness in patients with branch retinal vein occlusion. Am J Ophthalmol 2007; 143: 342-4.

[11] Noma H, Funatsu H, Mimura T, Harino S, Shimada K. Functionalmorphologic correlates in patients with branch retinal vein occlusion and macular edema. Retina 2011;31:2102-8.

[12] Thylefors B, Chylack LT Jr, Konyama K, et al. A simplified cataract grading system. Ophthalmic Epidemiol 2002; 9: 83-95.

[13] Noma H, Funatsu H, Mimura T, Shimada K. Macular sensitivity and morphology after intravitreal injection of triamcinolone acetonide for macular edema with branch retinal vein occlusion. Retina 2012; 32: 1844-52.

[14] Noma H, Funatsu H, Yamasaki M, et al. Pathogenesis of macular edema with branch retinal vein occlusion and intraocular levels of vascular endothelial growth factor and interleukin-6. Am J Ophthalmol 2005; 140: 256-61.

[15] Noma H, Minamoto A, Funatsu H, et al. Intravitreal levels of vascular endothelial growth factor and interleukin- 6 are correlated with macular edema in branch retinal vein occlusion. Graefes Arch Clin Exp Ophthalmol 2006; 244: 309-15.

[16] Noma H, Funatsu H, Yamasaki M, et al. Aqueous humour levels of cytokines are correlated to vitreous levels and severity of macular oedema in branch retinal vein occlusion. Eye 2008; 22: 42-8.

[17] Antonetti DA, Wolpert EB, DeMaio L, Harhaj NS, Scaduto RC Jr. Hydrocortisone decreases retinal endothelial cell water and solute flux coincident with increased content and decreased phosphorylation of occludin. J Neurochem 2002; 80: 667-77.

[18] Zhang X, Bao S, Lai D, Rapkins RW, Gillies MC. Intravitreal triamcinolone acetonide inhibits breakdown of the blood-retinal barrier through differential regulation of VEGF-A and its receptors in early diabetic rat retinas. Diabetes 2008; 57: 1026-33.

[19] McAllister IL, Vijayasekaran S, Chen SD, Yu DY. Effect of triamcinolone acetonide on vascular endothelial growth factor and occludin levels in branch retinal vein occlusion. Am J Ophthalmol 2009; 147: 838-46, 846 e1-2.

[20] Kurtz RM, Elner VM, Bian ZM, Strieter RM, Kunkel SL, Elner SG. Dexamethasone and cyclosporin A modulation of human retinal pigment epithelial cell monocyte chemotactic protein-1 and interleukin-8. Invest Ophthalmol Vis Sci 1997; 38: 436-45.

[21] Mizuno S, Nishiwaki A, Morita H, Miyake T, Ogura Y. Effects of periocular administration of triamcinolone acetonide on leukocyteendothelium interactions in the ischemic retina. Invest Ophthalmol Vis Sci 2007; 48: 2831-6.

[22] Miyamoto K, Khosrof S, Bursell SE, et al. Prevention of leukostasis and vascular leakage in streptozotocin-induced diabetic retinopathy via intercellular adhesion molecule-1 inhibition. Proc Natl Acad Sci USA 1999; 96: 10836-41. 
[23] Noma H, Funatsu H, Mimura T, Eguchi S, Shimada K. Inflammatory factors in major and macular branch retinal vein occlusion. Ophthalmologica 2012; 227: 146-52.
[24] Ota M, Tsujikawa A, Murakami T, et al. Association between integrity of foveal photoreceptor layer and visual acuity in branch retinal vein occlusion. Br J Ophthalmol 2007; 91: 1644-9.

(C) Noma et al.; Licensee Bentham Open.

This is an open access article licensed under the terms of the Creative Commons Attribution Non-Commercial License (http://creativecommons.org/licenses/by$\mathrm{nc} / 3.0 /$ ) which permits unrestricted, non-commercial use, distribution and reproduction in any medium, provided the work is properly cited. 